\title{
Numerical Computation of the Combined Specific Absorption Rates Induced in Human Head due to Multiple Independent Sources
}

\author{
Salah I. Yahya*, Yazen A. Khalil \\ Department of Software Engineering, Faculty of Engineering, Koya University, University Park, Danielle Mitterrand Boulevard, \\ Koya KOY45, Kurdistan Region of F.R. Iraq
}

\begin{abstract}
The combination of the specific absorption rates induced in human head due to multiple independent electromagnetic field sources is computed numerically. The scenario of this paper considers a human making a mobile call by a GSM-900 handset of internal antenna while working on a Laptop computer with Wi-Fi-enabled dipole-antenna broadcasting at $2.4 \mathrm{GHz}$. The mobile phone in hand and in close proximity to head at check-position is adopted, whereas, the Laptop computer having different Wi-Fi antenna orientations and positioned at different places, with respect to head, are examined. The results show how the specific absorption rates in head are combined when exposed to both sources, simultaneously. The numerical computation is achieved using a high resolution FDTD gridding; solved by a 3-D full-wave electromagnetic simulation software on a high performance workstation machine with Tesla GPU accelerator.
\end{abstract}

Keywords Antenna, FDTD, Human phantom, Mobile phone, Mobile phone antenna, SAR

\section{Introduction}

Owing to the enormous development in communication technologies, nowadays it is common to see people using different communication devices that have different independent electromagnetic field (EMF) sources, simultaneously, e.g., making a mobile phone call while working on a Laptop computer connected to a Wi-Fi network. In spite of the possible EM hazard caused by using the mobile communication devices in the vicinity of human head/body [1], using multiple EMF sources may increase the possibility of such hazard. Moreover, using a mobile phone accompanied by another EMF source may push the specific absorption rate (SAR) induced in the human head to cross the safety limit [2-4], at certain position and certain direction.

The interaction between multiple sources, themselves, and with human body has been investigated by many researchers. Human body exposure to multiple mobile phone sources inside enclosed spaces such as trains and elevators have been presented in $[5,6]$. The mechanisms of near-field interaction between dipoles and mobile phone models and homogeneous body models are examined in [7, 8]. The scenario of anatomically realistic head excited

* Corresponding author:

salah.ismaeel@koyauniversity.org (Salah I. Yahya)

Published online at http://journal.sapub.org/ijea

Copyright (C) 2015 Scientific \& Academic Publishing. All Rights Reserved by various sources including: plane waves, vertically and horizontally orientated dipoles positioned $8 \mathrm{~cm}$ in front and by the side of the head over the frequency range 0.5 to $4 \mathrm{GHz}$ is presented in [9].

In this paper a realistic case of using two different EMF sources, i.e., GSM-900 mobile phone handset and a Laptop computer with Wi-Fi antenna, is examined. The handheld mobile phone is in close proximity to head at cheek-position according to the IEEE Std. 1528 [10], whereas, the Laptop computer is positioned at different places, i.e., in front of the face, on the left-side of the head and on the right-side, with two possible antenna orientations, horizontal and vertical. In all these different scenarios, the head lies in the near-field region of the GSM-900 handset antenna radiation and in the far-field region of the Laptop computer $\mathrm{Wi}-\mathrm{Fi}$ antenna radiation, where the combined SAR in head is calculated for each scenario numerically using the Finite-Difference Time-Domain (FDTD) method with the assistance of the an EM solver (SEMCAD X) [11].

\section{Materials and Method}

The photo in Fig. 1 shows a realistic example of making a mobile call while sitting in front of a Laptop computer connected to Wi-Fi network. This realistic example will be considered throughout this paper with different Laptop positions while computing the combined SAR due to the multiple sources. 


\subsection{EMF Sources Models}

Two independent EMF sources have been considered to compute the Peak Spatial-Average SAR[IEEE] over $1 \mathrm{~g}$ $\left(\mathrm{SAR}_{1 \mathrm{~g}}\right)$ in human head due to the individual field of each source and then due to the combined fields of both sources. The first EMF source is a handset antenna, whereas, the second source is a Laptop Wi-Fi antenna. A semirealistic handset model using a single-band probe-fed rectangular patch antenna with shorting plate at the edge was designed and used [12] to simulate the most common handsets available commercially nowadays. The maximum physical dimensions of the handset are $110 \mathrm{~mm} \times 44 \mathrm{~mm} \times 13 \mathrm{~mm}$, whereas; the multilayer PCB dimensions are $97 \mathrm{~mm} \times 37 \mathrm{~mm} \times 1 \mathrm{~mm}$. The handset antenna is tuned at $900 \mathrm{MHz}(\mathrm{GSM}-900)$ and working at $250 \mathrm{~mW}$ antenna input power. The $\left|\mathrm{S}_{11}\right|$ at the tuned frequency is $-18.7 \mathrm{~dB}$. The Laptop Wi-Fi antenna is a dipole antenna tuned at $2.4 \mathrm{GHz}$ with $600 \mathrm{~mW}$ input power. The dipole length is $53 \mathrm{~mm}$ and the diameter is $2.5 \mathrm{~mm}$. The $\left|\mathrm{S}_{11}\right|$ at the tuned frequency is $-18.27 \mathrm{~dB}$. The Laptop computer model used in simulation is 15.6" widescreen screen with dimensions $(\mathrm{W} \times \mathrm{D} \times \mathrm{H})$ of $376 \mathrm{~mm} \times 245 \mathrm{~mm} \times 34.3 \mathrm{~mm}$. The Laptop parts that considered in simulation were plastic and glass.

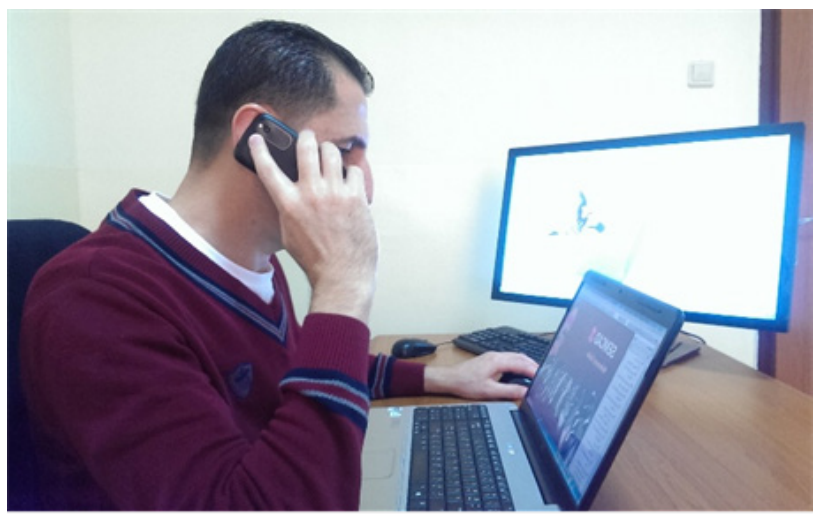

Figure 1. A photo showing a realistic usage of mobile phone while sitting in front of a Laptop computer connected to Wi-Fi network

\subsection{Human Head/Hand Models}

An anatomically realistic 3D model of human head and shoulder (VH_head) of 38 years old male, based on the Visible Human Project and available with SEMCAD X [11], has been used in this paper. A 52 recognized tissues of the $\mathrm{VH}$ head model were defined according to the material data base available in [11]. The head data has a $2 \mathrm{~mm}$ resolution.

A realistic posable right-hand model composed of three tissues; skin, muscles and bones, available from SPEAG [11], was used to simulate the user's hand. Fig. 2-a shows the hand model grasping the handset and Fig. 2-b shows the handheld mobile phone in close proximity to $\mathrm{VH} \_\mathrm{Head}$.

\subsection{Numerical Approach}

The numerical computation of the individual and combined $\mathrm{SAR}_{1 \mathrm{~g}}$ was achieved using the FDTD method that proposed by Kane Yee in 1966 [13]. A licensed SEMCAD X, version 14.8.6 Aletsch, commercially available from SPEAG [11] was used to achieve the results. A high performance workstation machine hp Z420 [14] (Intel ${ }^{\circledR}$ Xeon ${ }^{\circledR}$ CPU E5-1620 v2@3.70GHz 15MB 1866,6 processor cores, 48GB memory) with NVIDIA Quadro K2000 graphic card is used, and accelerated by a Tesla ${ }^{\circledR}$ GPU ${ }^{\circledR}$ K20 [15] using NVIDIA CUDA driver and based on the NVIDIA Kepler ${ }^{\mathrm{TM}}$ Architecture (2496 CUDA cores and 5GB memory).

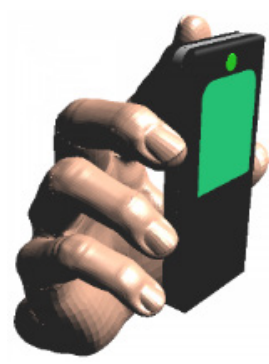

(a)

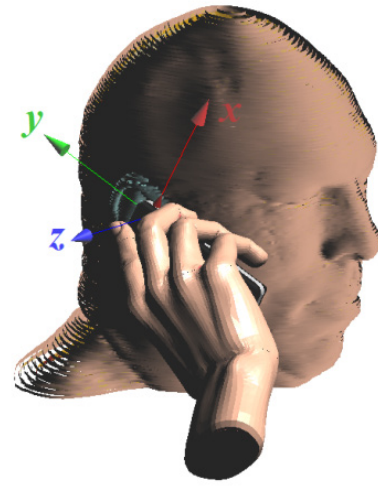

(b)
Figure 2. Perspective view of (a) Posable right-hand grasping the handset and (b) The handheld mobile phone in close proximity to $\mathrm{VH}_{-}$head at cheek- position

\section{FDTD Grid Generation}

Six different scenarios have been considered to calculate the combined $\mathrm{SAR}_{1 \mathrm{~g}}$ induced in head due to the mobile phone and Wi-Fi antenna fields, simultaneously. In all adopted scenarios the handset is in close proximity to rightside of the head at cheek-position;

1. Making a mobile call in front of a Laptop computer uses a vertical Wi-Fi dipole antenna. The distance between the dipole antenna and the forehead is $25 \mathrm{~cm}$. The two sources are with cross polarization.

2. Making a mobile call while the Laptop computer on the right-side of the head. The Laptop uses a vertical $\mathrm{Wi}-\mathrm{Fi}$ dipole antenna and it is in a distance of $25 \mathrm{~cm}$ from the head side. The two sources are with cross polarization.

3. Making a mobile call while the Laptop computer on the left-side of the head. The Laptop uses a vertical Wi-Fi dipole antenna and it is in a distance of $25 \mathrm{~cm}$ from the head side. The two sources are with cross polarization.

4. Making a mobile call in front of a Laptop computer uses a horizontal Wi-Fi dipole antenna. The distance between the dipole antenna and the forehead is $25 \mathrm{~cm}$. The two sources are with same polarization.

5. Making a mobile call while the Laptop computer on the right-side of the head. The Laptop uses a horizontal Wi-Fi dipole antenna and it is in a distance of $25 \mathrm{~cm}$ from the head side. The two sources are with cross polarization. 
6. Making a mobile call while the Laptop computer on the left-side of the head. The Laptop uses a horizontal Wi-Fi dipole antenna and it is in a distance of $25 \mathrm{~cm}$ head side. The two sources are with cross polarization.

Fig. 3 shows the SEMCAD X CAD model of scenario \#1 and scenario \#4, depending on the WiFi antenna orientation, vertically or horizontally, respectively.

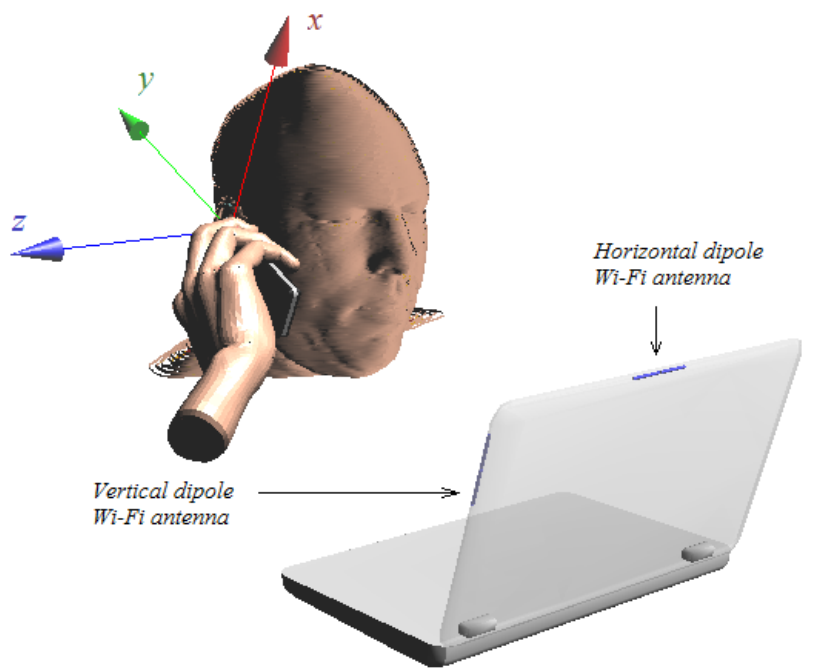

Figure 3. Perspective views of SEMCAD X CAD model to simulate the realistic example shown in in photo of Fig. 1 with two possible orientations of the WiFi Antenna

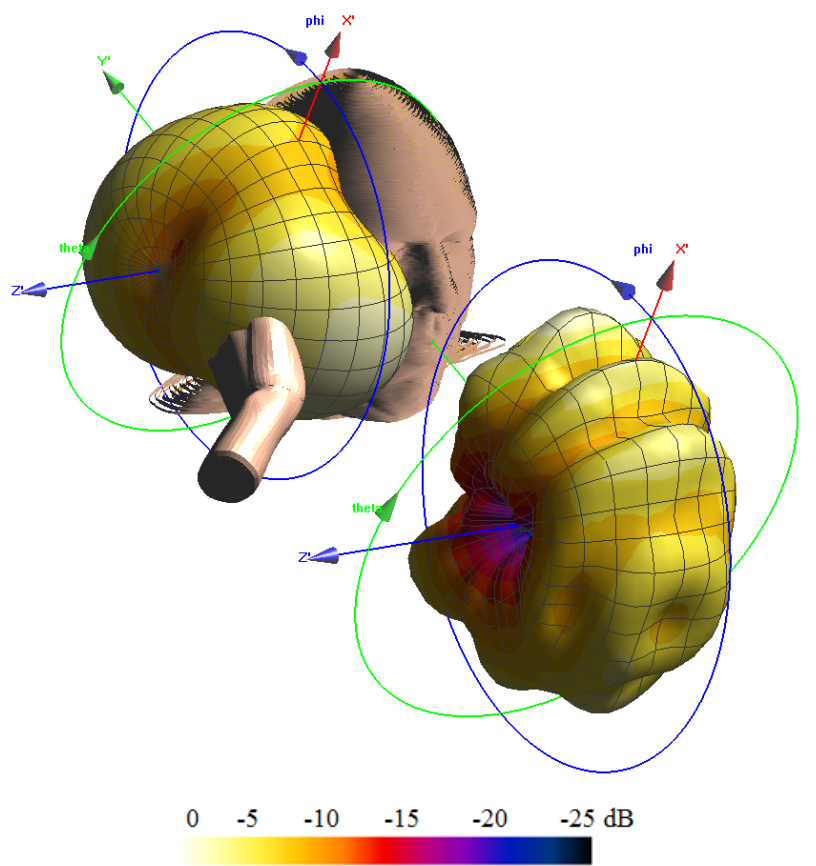

Figure 4. The E_total radiation beam pattern of both 900 and $2400 \mathrm{MHz}$ sources for scenario \#4. The Laptop computer is not shown here to make the patterns more visible

For the FDTD grid setting, a minimum spatial resolution (Yee cell) of $0.5 \mathrm{~mm}$ was set in the $x, y$, and $z$ directions with grading ratio of 1.2. The simulations were run for at least fifteen cycles and until stability was achieved. The absorbing boundary conditions (ABCs) are set as a uniaxial perfectly matched layer (UPML) mode with a very high strength thickness, where minimum level of absorption at the outer boundary is $(>99.9 \%)$. The number of grid cells needed for each scenario was 52.7628 Mcells.

Fig. 4 shows the electric field radiation beam pattern of both 900 and $2400 \mathrm{MHz}$ sources, scenario \#4. As it is shown in this figure, both sources have the same polarization and their axes are parallel. For the handset antenna; $0 \mathrm{~dB}=1.349 \mathrm{~V} / \mathrm{m}$ with antenna input power normalized to $250 \mathrm{~mW}$, whereas, for the Wi-Fi antenna; $0 \mathrm{~dB}=8.358 \mathrm{~V} / \mathrm{m}$ with antenna input power of $600 \mathrm{~mW}$. It is obvious how both radiation patterns are affected by the presence of the hand, head and Laptop computer.

\section{Numerical Results and Discussion}

Computing the SAR due to individual source is a straightforward process. SEMCAD X has the ability to store the electric fields at each Yee cell interface at different frequencies. Therefore, the SAR at each point in the head can be calculated in the post processing from the individual frequencies. The final step then is to calculate the maximum $1 \mathrm{~g}$ SAR from the local SAR at each point.

Table 1 lists the computed $\mathrm{SAR}_{1 \mathrm{~g}}$ in head due to the individual sources and the combined $\mathrm{SAR}_{1 \mathrm{~g}}$ of the two sources for each scenario. The numerical computation considered the two possible Wi-Fi antenna positions, vertical and horizontal.

Fig. 5 shows the sliced distribution of the $\mathrm{SAR}_{1 \mathrm{~g}}$ in head along the $y z$-plane due to the individual field of the 900 and $2400 \mathrm{MHz}$ sources and their combined field. The $2400 \mathrm{MHz}$ antenna is in vertical position along the $x$-axis and cross polarized with the $900 \mathrm{MHz}$ patch antenna.

Fig. 6 shows the same $\mathrm{SAR}_{1 \mathrm{~g}}$ sliced distributions but the $2400 \mathrm{MHz}$ antenna is in horizontal position along the $z$-axis.

Table 1. The numerical computation results of the $\mathrm{SAR}_{1 \mathrm{~g}}(\mathrm{~W} / \mathrm{kg})$ in head due to the individual field of each source and the combine field, as well, for the six adopted scenarios

\begin{tabular}{|c|c|c|c|c|}
\hline & Source & Front* & Right* & Left* \\
\hline \multirow{2}{*}{$\begin{array}{c}\text { Mobile Phone } \\
\text { with vertical }\end{array}$} & $900 \mathrm{MHz}$ & 0.422 & 0.422 & 0.422 \\
\cline { 2 - 5 } Wi-Fi antenna & $2400 \mathrm{MHz}$ & 0.435 & 0.128 & 0.163 \\
\cline { 2 - 5 } & Combined & 0.440 & 0.502 & 0.423 \\
\hline \multirow{2}{*}{$\begin{array}{c}\text { Mobile Phone } \\
\text { with horizontal } \\
\text { Wi-Fi antenna }\end{array}$} & $900 \mathrm{MHz}$ & 0.422 & 0.422 & 0.422 \\
\cline { 2 - 5 } & $2400 \mathrm{MHz}$ & 0.176 & 0.094 & 0.256 \\
\cline { 2 - 5 } & Combined & 0.488 & 0.458 & 0.427 \\
\hline
\end{tabular}

*This is the position of the Wi-Fi $2400 \mathrm{MHz}$ source with respect to head

The results that presented in Table 1 and sketched in Figures 5 and 6 show the following;

1. The combined $\mathrm{SAR}_{1 \mathrm{~g}}$ due to the two sources is coincide with the following relation that given in [9]:

$$
\begin{gathered}
\operatorname{Max}\left(\mathrm{SAR}_{1 \mathrm{~g}, \mathrm{fl}}, \mathrm{SAR}_{1 \mathrm{~g}, \mathrm{f} 2}\right) \leq \mathrm{SAR}_{1 \mathrm{~g}, \text { total }} \\
\leq\left(\mathrm{SAR}_{1 \mathrm{~g}, \mathrm{fl}}+\mathrm{SAR}_{1 \mathrm{~g}, \mathrm{f} 2}\right)
\end{gathered}
$$


2. For the (x-axis) vertical $2400 \mathrm{MHz}$ source, the maximum $\mathrm{SAR}_{1 \mathrm{~g}}$ in head occurs when the source in front of the face, whereas, for the (y and $z$-axis) horizontal source the maximum $\mathrm{SAR}_{1 \mathrm{~g}}$ occurs when the source on the left-side. For both $2400 \mathrm{MHz}$ source orientations, the minimum $\mathrm{SAR}_{1 \mathrm{~g}}$ in head occurs when the source is on the right-side. This is because the hand and phone are sandwiched between the source and head, and absorb part of the source field.

3 . For the (x-axis) vertical $2400 \mathrm{MHz}$ source, the maximum combined $\mathrm{SAR}_{1 \mathrm{~g}}(0.502 \mathrm{~W} / \mathrm{kg})$ occurs when the source on the right-side (scenario \#2), whereas, the maximum combined $\mathrm{SAR}_{1 \mathrm{~g}}(0.488 \mathrm{~W} / \mathrm{kg})$ occurs with Scenario \#4.

4. In general, scenario \#2 among the six scenarios gives the highest combined $\mathrm{SAR}_{1 \mathrm{~g}}$ in head. Making a mobile call in presence of a Laptop computer with activated vertical Wi-Fi antenna on the right-side of the head may increase the $\mathrm{SAR}_{1 \mathrm{~g}}$ by $20 \%$, as compared with scenario of a mobile call with no Laptop presence.

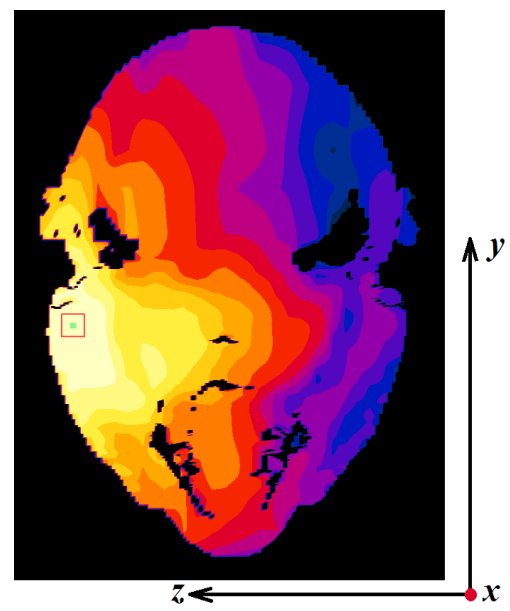

(a) $900 \mathrm{MHz}$ source

$\mathrm{SAR}_{1 \mathrm{~g}}=0.421 \mathrm{~W} / \mathrm{kg}$ positioned at $x=-18.9, y=-23.2, z=-22.4 \mathrm{~mm}$

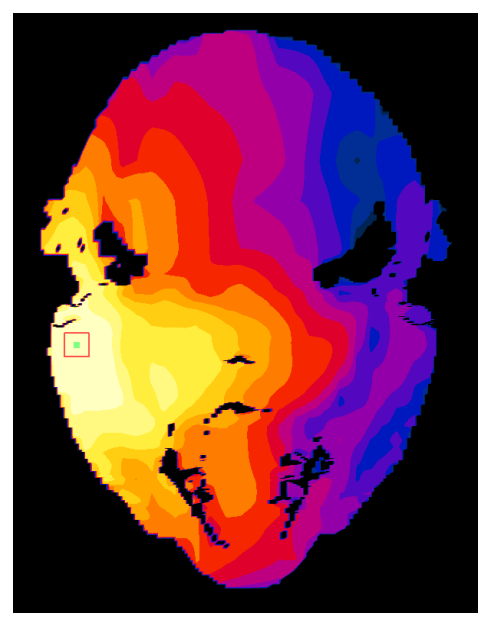

(d) $900 \mathrm{MHz}$ source

$\mathrm{SAR}_{1 \mathrm{~g}}=0.421 \mathrm{~W} / \mathrm{kg}$ positioned at $x=-18.9, y=-23.2, z=-22.4 \mathrm{~mm}$

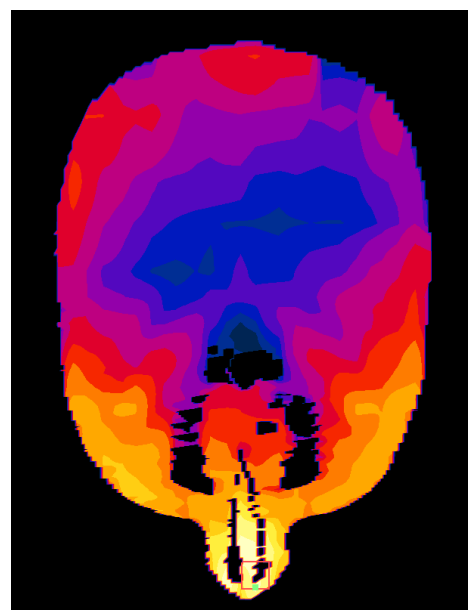

(b) $2400 \mathrm{MHz}$ source in front of the face $\mathrm{SAR}_{1 \mathrm{~g}}=0.435 \mathrm{~W} / \mathrm{kg}$ positioned at $x=29.5, y=-113, z=-95.6 \mathrm{~mm}$

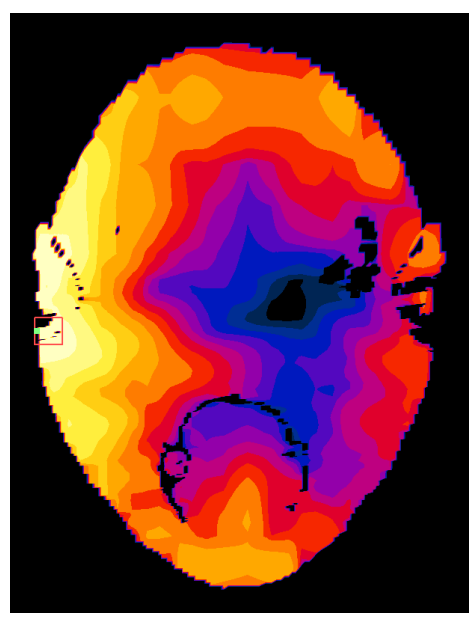

(e) $2400 \mathrm{MHz}$ source right-side of head $\mathrm{SAR}_{1 \mathrm{~g}}=0.128 \mathrm{~W} / \mathrm{kg}$ positioned at $x=-28.1, y=-15.1, z=-9.3 \mathrm{~mm}$

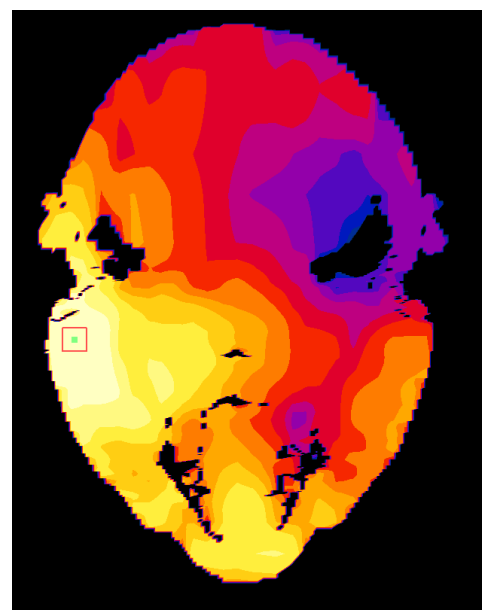

(c) Combined $\mathrm{SAR}_{1 \mathrm{~g}}$ $\mathrm{SAR}_{1 \mathrm{~g}}=0.440 \mathrm{~W} / \mathrm{kg}$ positioned at $x=-19.3, y=-23.5, z=-22.4 \mathrm{~mm}$

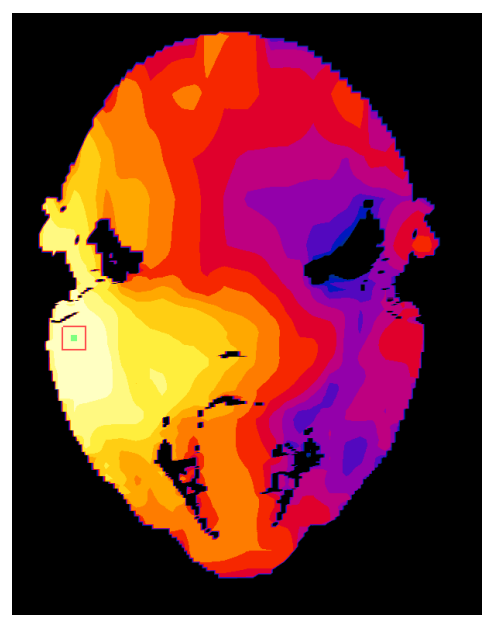

(f) Combined SAR $\mathrm{S}_{1 \mathrm{~g}}$ $\mathrm{SAR}_{1 \mathrm{~g}}=0.502 \mathrm{~W} / \mathrm{kg}$ positioned at $x=-19.3, y=-22.6, z=-22.4 \mathrm{~mm}$ 


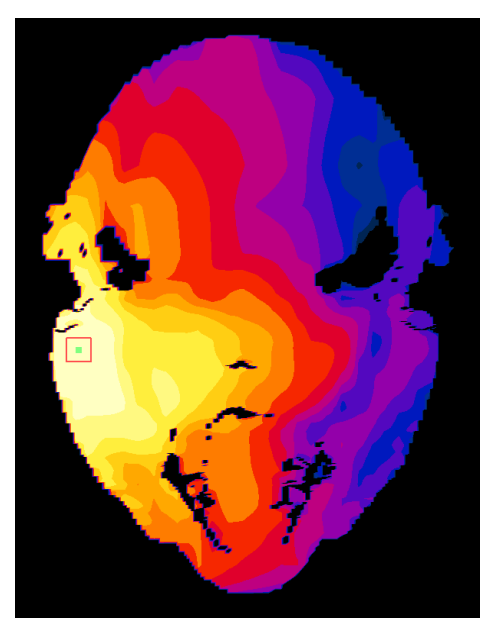

(g) $900 \mathrm{MHz}$ source

$\mathrm{SAR}_{1 \mathrm{~g}}=0.421 \mathrm{~W} / \mathrm{kg}$ positioned at $x=-18.9, y=-23.2, z=-22.4 \mathrm{~mm}$

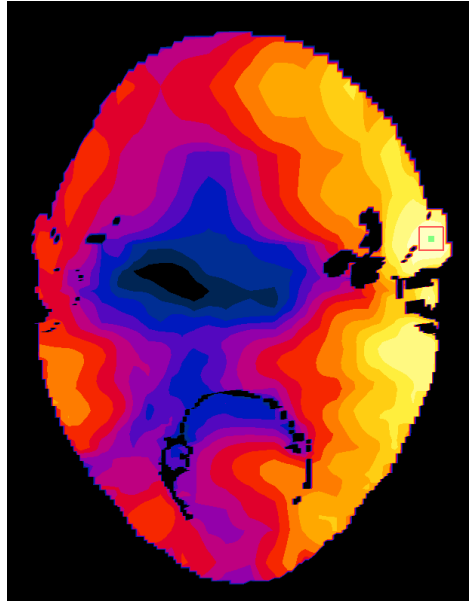

(h) 2400MHz source left-side of head $\mathrm{SAR}_{1 \mathrm{~g}}=0.163 \mathrm{~W} / \mathrm{kg}$ positioned at $x=-27.5, y=-17.5, z=-244 \mathrm{~mm}$

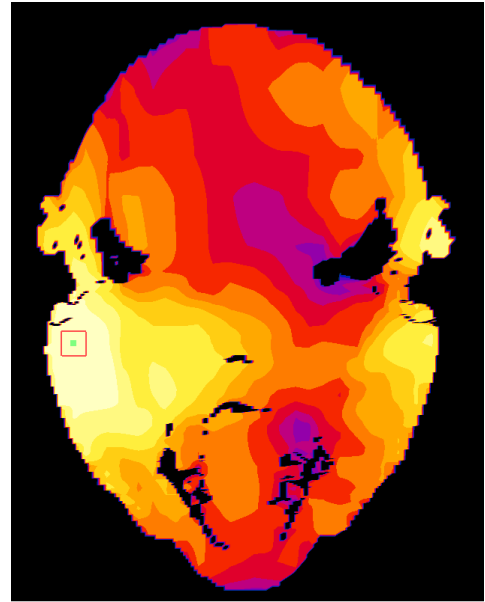

(i) Combined $\mathrm{SAR}_{1 \mathrm{~g}}$ $\mathrm{SAR}_{1 \mathrm{~g}}=0.423 \mathrm{~W} / \mathrm{kg}$ positioned at $x=-18.9, y=-23.2, z=-22.4 \mathrm{~mm}$

Figure 5. Sliced distribution of the $\mathrm{SAR}_{1 \mathrm{~g}}$ in head along the $y z$-plane for the $900 \mathrm{MHz}$ source normalized to $250 \mathrm{~mW}$ input power, $2400 \mathrm{MHz}$ source normalized to $600 \mathrm{~mW}$ and for the combined field of both sources. The Wi-Fi dipole antenna is in ( $x$-axis) vertical position; (a), (b) and (c) The Wi-Fi antenna is in front of the face, (d), (e) and (f) The Wi-Fi antenna is on the right-side of the head and (g), (h) and (i) The Wi-Fi antenna is on the left-side of the head

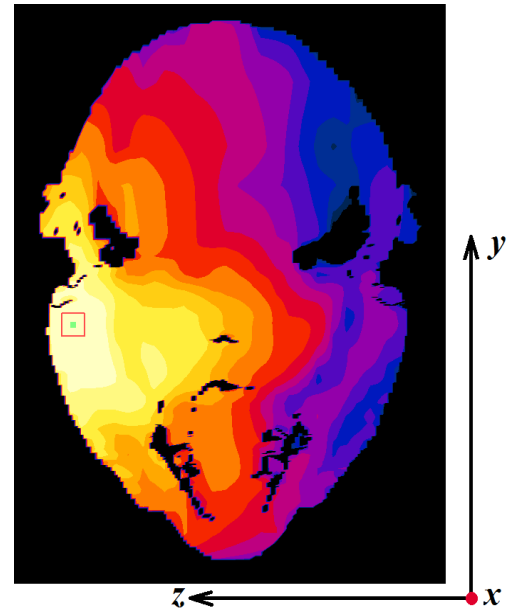

(a) $900 \mathrm{MHz}$ source

$\mathrm{SAR}_{1 \mathrm{~g}}=0.421 \mathrm{~W} / \mathrm{kg}$ positioned at $x=-18.9, y=-23.2, z=-22.4 \mathrm{~mm}$

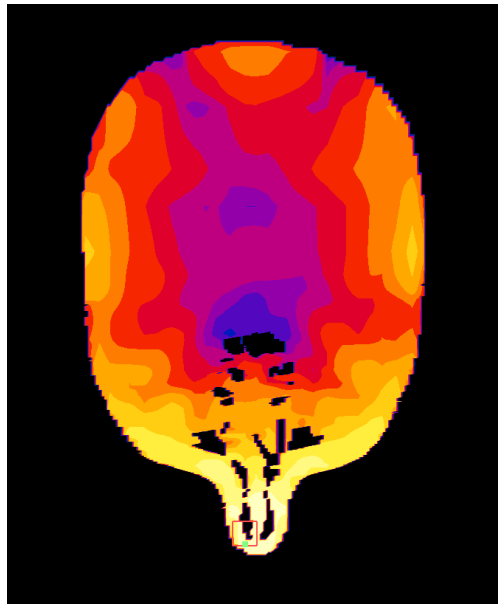

(b) $2400 \mathrm{MHz}$ source in front of the face $\mathrm{SAR}_{1 \mathrm{~g}}=0.176 \mathrm{~W} / \mathrm{kg}$ positioned at $x=33.3, y=-113, z=-86.7 \mathrm{~mm}$

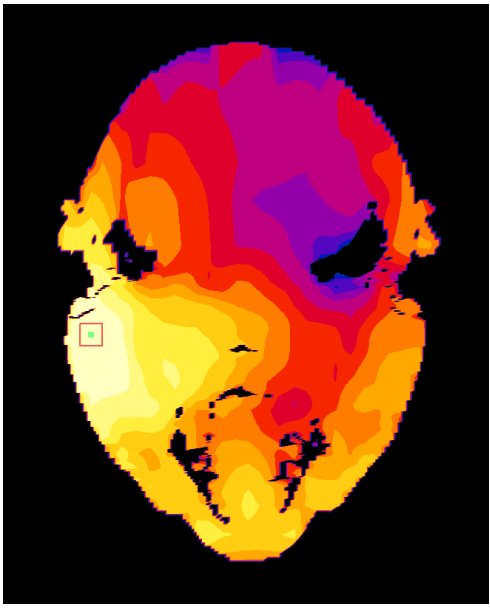

(c) Combined $\mathrm{SAR}_{1 \mathrm{~g}}$ $\mathrm{SAR}_{1 \mathrm{~g}}=0.488 \mathrm{~W} / \mathrm{kg}$ positioned at $x=-19.7, y=-23.2, z=-22.4 \mathrm{~mm}$ 


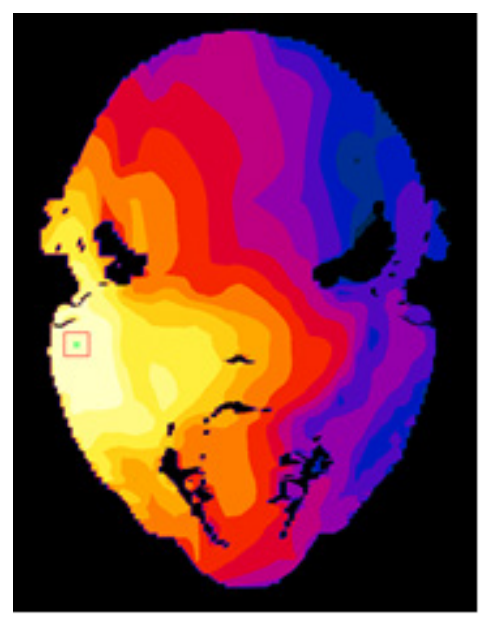

(d) $900 \mathrm{MHz}$ source

$\mathrm{SAR}_{1 \mathrm{~g}}=0.421 \mathrm{~W} / \mathrm{kg}$ positioned at $x=-18.9, y=-23.2, z=-22.4 \mathrm{~mm}$

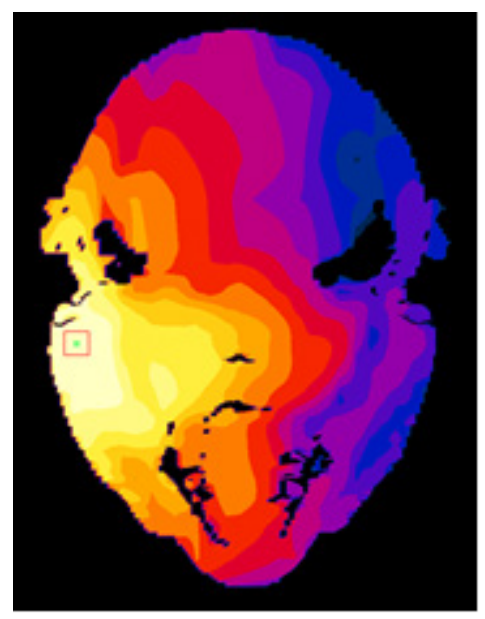

(g) $900 \mathrm{MHz}$ source

$\mathrm{SAR}_{1 \mathrm{~g}}=0.421 \mathrm{~W} / \mathrm{kg}$ positioned at $x=-18.9, y=-23.2, z=-22.4 \mathrm{~mm}$

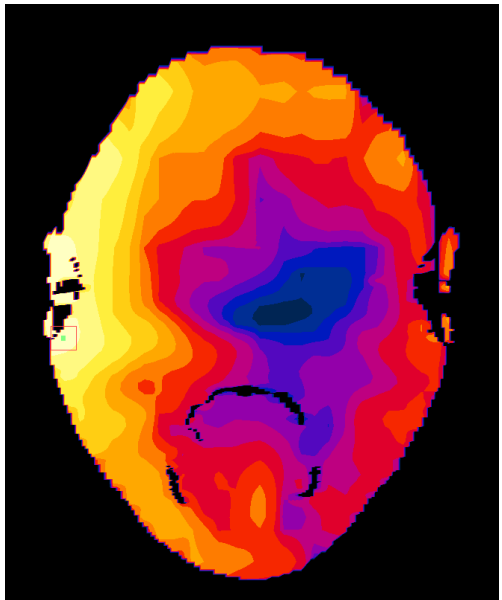

(e) $2400 \mathrm{MHz}$ source right-side of head $\mathrm{SAR}_{1 \mathrm{~g}}=0.094 \mathrm{~W} / \mathrm{kg}$ positioned at $x=-32.9, y=4.9, z=-24.4 \mathrm{~mm}$

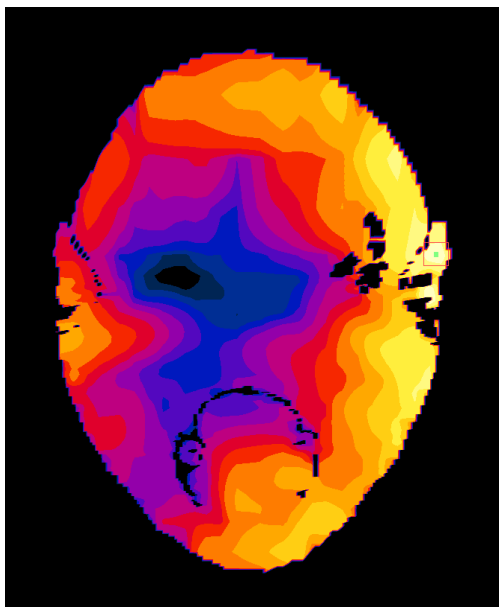

(h) $2400 \mathrm{MHz}$ source left-side of head $\mathrm{SAR}_{1 \mathrm{~g}}=0.256 \mathrm{~W} / \mathrm{kg}$ positioned at $x=-28.4, y=-19, z=-256 \mathrm{~mm}$

0

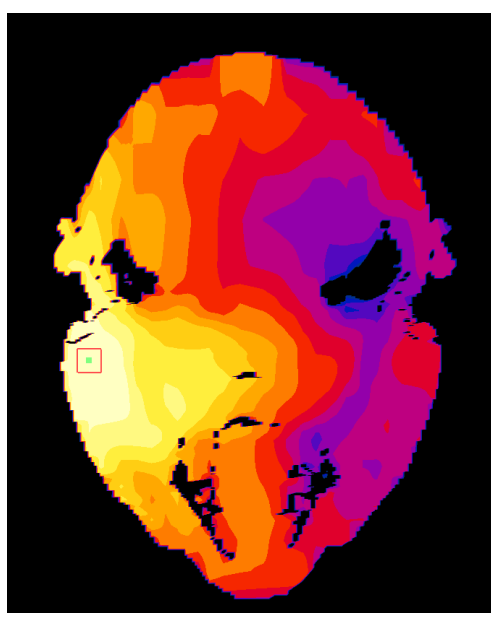

(f) Combined $\mathrm{SAR}_{1 \mathrm{~g}}$ $\mathrm{SAR}_{1 \mathrm{~g}}=0.458 \mathrm{~W} / \mathrm{kg}$ positioned at $x=-19.3, y=-23.2, z=-22.4 \mathrm{~mm}$

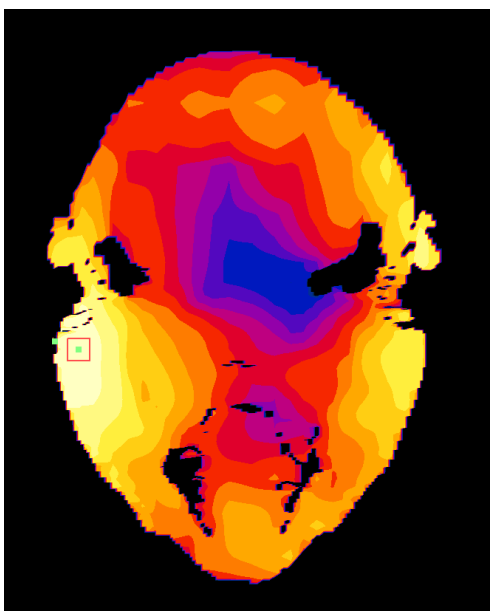

(i) Combined $\mathrm{SAR}_{1 \mathrm{~g}}$ $\mathrm{SAR}_{1 \mathrm{~g}}=0.427 \mathrm{~W} / \mathrm{kg}$ positioned at $x=-21.1, y=-19.5, z=-10.8 \mathrm{~mm}$

Figure 6. Sliced distribution of the $\mathrm{SAR}_{1 \mathrm{~g}}$ in head along the $y z$-plane for the $900 \mathrm{MHz}$ source normalized to $250 \mathrm{~mW}$ input power, $2400 \mathrm{MHz}$ source normalized to $600 \mathrm{~mW}$ and for the combined field of both sources; (a), (b) and (c) The Wi-Fi antenna is in ( $z$-axis) horizontal position, in front of the face, (d), (e) and (f) The Wi-Fi antenna is in ( $y$-axis) horizontal position, on the right-side of the head and (g), (h) and (i) The Wi-Fi antenna is in ( $y$-axis) horizontal position, on the left-side of the head

\section{Conclusions}

This paper showed how the specific absorption rates induced in human head are combined due to the fields of multiple sources, i.e., GSM-900 handset and a Laptop computer with activated Wi-Fi dipole antenna. Different Laptop computer positions with respect to head and different possible Wi-Fi antenna orientations inside the Laptop computer were considered. The numerical results that based on the FDTD method showed a $20 \%$ increase in the $\mathrm{SAR}_{1 \mathrm{~g}}$ in head while making a mobile call via GSM-900 in presence of a Laptop computer on the right-side and with activated vertical Wi-Fi antenna, as compared with the scenario of no Laptop presence. 


\section{REFERENCES}

[1] SCENHIR (2009). Scientific Committee on Emerging and Newly Identified Health Risks (SCENIHR) Updated Opinion on Possible Effects of Electromagnetic (EMF) on Human Health. European Commission Health \& Consumers Directorate-General.

[2] (1997) Evaluating Compliance with FCC Guidelines for Human Exposure to Radio Frequency Electromagnetic Field, Supplement C to OET Bulletin 65 (Edition 9701), Federal Communications Commission (FCC), Washington, DC, USA.

[3] (2006) IEEE Standard for Safety Levels with Respect to Human Exposure to Radiofrequency Electromagnetic Fields, $3 \mathrm{kHz}$ to $300 \mathrm{GHz}$.

[4] (2001) Product standard to demonstrate the compliance of mobile phones with the basic restrictions related to human exposure to electromagnetic fields $(300 \mathrm{MHz}-3 \mathrm{GHz})$, European Committee for Electrical Standardization (CENELEC), EN 50360, Brussels.

[5] T. Hondou, T. Ueda, Y. Sakata, N. Tanigawa, T. Suzuki, T. Kobayashi, and K. Ikeda, "Passive Exposure to Mobile Phones: Enhancement of Intensity by Reflection," Journal of the Physical Society of Japan, vol. 75, pp. 084801-084805, 2006.

[6] M. Siegbahn, H. Gradin, B. Thors, and C. Törnevik, "RF exposure from multiple mobile phones in an enclosed environment," Bioelectromagnetics Society Annual Meeting, Cancun, Mexico, 2006.

[7] B. Derat, A. Cozza, and J. C. Bolomey, "Influence of source phantom multiple interactions on the field transmitted in a flat phantom," in Proc. 18th Int. Zurich Symposium on Electrom. Compatibility (EMC 2007), Zurich, Switzerland, 2007.
[8] B. Derat, and A. Cozza, "Analysis of the transmitted field amplitude and SAR modification due to mobile terminal - flat phantom multiple interactions," in Proc. 2nd Euro. Conf. Antennas and Propagation (EuCAP 2007), Edinburgh, UK, 2007.

[9] W.G. Whittow, C. Panagamuwa, B. Derat and I. Morrow, "Correlation of specific absorption rates in the human head due to multiple independent sources," in Proc. of Loughborough Antennas and Propagation Conference, 16-17 November 2009, Burleigh Court Conference Centre, Loughborough University, UK, pp. 405-408, 2009.

[10] (2003) IEEE Standard-1528, "IEEE Recommended Practice for Determining the Peak Spatial-Average Specific Absorption Rate (SAR) in the Human Head from Wireless Communications Devices: Measurement Techniques," December 2003, USA.

[11] SEMCAD-X, 2014. Version 14.8 Altesch. Reference Manual, Simulation Platform for Electromagnetic Compatibility, Antenna Design and Dosimetry, SPEAG - Schmid \& Partner Engineering AG: http://www.semcad.com, accessed January 2014.

[12] S. Al-Mously, and M. Abousetta, "Anticipated Impact of Hand-Hold Position on the Electromagnetic Interaction of Different Antenna Types/Positions and a Human in Cellular Communications. International Journal of Antennas and Propagation (IJAP), 22 pages, 2008.

[13] K. Yee, "Numerical solution of initial boundary value problems involving Maxwell's equations in isotropic media," IEEE Transaction on Antennas and Propagation, vol. 14, no. 3, pp. 302-307, 1966.

[14] Hewlett-Packard workstations, http://www8.hp.com/us/en/ca mpaigns/workstations/z420.html, accessed January 2014.

[15] 'PNY Technologies',http://www.pny.eu/product/p-8-70-596/ NVIDIA-Tesla/Tesla-K20-Card/, accessed January 2014. 